\title{
OHMIC CONTACT WITH ENHANCED STABILITY TO POLYCRYSTALLINE SILICON CARBIDE VIA CARBON INTERFACIAL LAYER

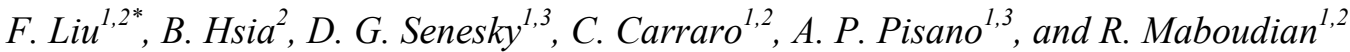 \\ ${ }^{1}$ Berkeley Sensor \& Actuator Center, Berkeley, California, USA \\ ${ }^{2}$ Department of Chemical Engineering, University of California at Berkeley, Berkeley, California, USA \\ ${ }^{3}$ Department of Mechanical Engineering, University of California at Berkeley, Berkeley, California, USA
}

\begin{abstract}
The development of electrical contacts to silicon carbide with low specific resistivity and stability is a critical requirement for harsh environment MEMS applications. In this paper, we present a novel method to lower the ohmic contact resistivity and enhance the stability of $\mathrm{Pt}$ contacts to polycrystalline 3C-SiC (poly-SiC) operated at elevated temperatures. In particular, nanocrystalline graphite is grown at the interface between poly-SiC and $\mathrm{Pt}$. The contact resistance of $\mathrm{Pt} / \mathrm{C} / \mathrm{SiC}$ is found to be half the value of $\mathrm{Pt} / \mathrm{SiC}$ at room temperature. In addition, the temperature dependence of the contact resistivity results show that with a carbon interfacial layer, stable ohmic contacts to poly-SiC are achieved at $540^{\circ} \mathrm{C}$ temperature in air.
\end{abstract}

\section{INTRODUCTION}

Recently, for industries such as automobile, petroleum and aerospace, there has been growing interest in harsh environment electronic and sensor technologies. Harsh environment, involving high temperature, high radiation, corrosion and erosion, requires thermally stable and robust materials for device applications. Silicon carbide is well known for its high mechanical strength, chemical stability, high thermal conductivity and electrical stability at elevated temperatures [1]. As a consequence, $\mathrm{SiC}$ electronics and microelectromechanical system (MEMS) devices have attracted much attention [2, 3]. For these $\mathrm{SiC}$ semiconductor devices, one of the most critical processes is the formation of low resistivity and thermally stable ohmic contacts for electrical contacts and interconnects.

Generally, an ohmic contacts to single crystalline $4 \mathrm{H}, 6 \mathrm{H}$ and $3 \mathrm{C}-\mathrm{SiC}$ are formed by deposition of metals or metal alloys on highly doped $\mathrm{SiC}$ films, followed by high temperature annealing. Various metal-to-SiC ohmic contacts have been reported for n-type $\mathrm{SiC}$ metallization [4]. For example, it has been reported that Ni can form low ohmic contact to n-type $\mathrm{SiC}$ [4]. However, the oxidation of $\mathrm{Ni}$ is found to occur at temperatures as low as $300{ }^{\circ} \mathrm{C}$ in air, with subsequent increase in the contact resistivity (by several orders of magnitude within a few hours) [5]. Compared to other metals, Pt, with its high thermal stability and high phase change temperature, is an outstanding candidate for $\mathrm{SiC}$ metallization. It is know polycrystalline $\mathrm{SiC}$ can be deposited at lower temperature compared to single crystalline $\mathrm{SiC}$, thus is compatible for MEMS process. Although $\mathrm{Pt}$ to poly-SiC contact has been reported previously $[4,5]$, the effect of interfacial chemistry on the Pt to poly-SiC contact has not been studied.

It was reported that the presence of a $\mathrm{C}$-rich layer at the SiC-nickel interface could be responsible for the low resistivity ohmic contact formation [6]. Among the various carbon forms, graphite holds the distinction of being the most stable form of carbon under standard conditions. The presence of a graphitic carbon layer at the interface between the metal and $\mathrm{SiC}$ not only could lower the contact resistivity, but also could build a barrier to diffusion and reactions between the metal and $\mathrm{SiC}$ at high temperature. Therefore, the graphitization of the $\mathrm{SiC}$ film before metallization could improve its metallization performance afterwards. Recently, graphene, a single layer of graphite, has been synthesized on single crystalline $\mathrm{SiC}$ by $\mathrm{Si}$ sublimation from a $\mathrm{SiC}$ substrate in an ultrahigh vacuum (UHV) or inert-ambient annealing chamber [7]. This process is compatible with planar semiconductor processing. In contrast to the post metal deposition annealing, $\mathrm{SiC}$ film pre-annealing could play a critical role in its metallization behavior.

The objective of this paper is to demonstrate thermally stable, low resistivity ohmic contacts to poly-SiC films for harsh environment MEMS applications. Graphitized poly-SiC film metallization is studied in comparison with the as-deposited poly-SiC film. In particular, the poly-SiC film is annealed at 1300 ${ }^{\circ} \mathrm{C}$ in an UHV environment, resulting in the growth of a nanocrystalline graphite layer. The contact resistivity measurements show that $\mathrm{Pt} / \mathrm{C} / \mathrm{SiC}$ contact resistivity is reduced to half the value of $\mathrm{Pt} / \mathrm{SiC}$ at room temperature. Furthermore, the $\mathrm{Pt} / \mathrm{C} / \mathrm{SiC}$ contact resistivity changes minimally from room temperature to $540{ }^{\circ} \mathrm{C}$ in the air, while the $\mathrm{Pt} / \mathrm{SiC}$ increases from $1.3 \times 10^{-5} \Omega . \mathrm{cm}^{2}$ to $2.5 \times 10^{-5} \Omega . \mathrm{cm}^{2}$. The results yield valuable information on $\mathrm{SiC}$ metallization stability and approaches to enhancing it, and may open the door to investigations of various metals to graphitized $\mathrm{SiC}$ contact studies.

\section{EXPERIMENTAL \\ Fabrication process}

In this work, the circular transmission line model (CTLM) [8] method is used to characterize the contact behavior and contact resistivity (Fig.1). The advantage of this structure is that only one lithography step is needed. The fabrication process of the as-deposited and annealed poly-SiC CTLM structures are shown in Fig.2. Nitrogen-doped (in-situ) poly-SiC films are grown by low pressure chemical vapor deposition (LPCVD) at $800{ }^{\circ} \mathrm{C}$, using methylsilane and dichlorosilane precursors. The details of the film deposition process can be found in Ref. [9]. Poly-SiC film thickness is $2.5 \mu \mathrm{m}$, with the resistivity of $0.01 \Omega-\mathrm{cm}$. The poly-SiC film is electrically isolated from $\mathrm{Si}$ (100) substrate by 1 $\mu \mathrm{m} \mathrm{LPCVD}$ low temperature grown silicon oxide. After poly-SiC film deposition, samples are annealed in a UHV chamber $\left(\sim 10^{-9}\right.$ Torr) at $1300{ }^{\circ} \mathrm{C}$ for $5 \mathrm{~min}$. Raman (HORIBA Jobin Yvon) spectra are used to characterize the carbon structure on top of the annealed poly-SiC surface. Further analysis of raman spectra will be discussed in later sections. The annealed and the as-deposited samples are dipped in HF to remove oxide, and then are patterned by photolithography of $1 \mu \mathrm{m}$ g-line and $1 \mu \mathrm{m}$ i-line to yield an undercut profile, which disallows sidewall coverage in the metal deposition step, yielding smooth edges. Then, $200 \mathrm{~nm}-\mathrm{Pt}$ is sputtered in an Edwards RF sputter coater, followed by lift-off in acetone. Finally, the annealed samples are exposed to $\mathrm{O}_{2}$ plasma to remove the nanocrystalline graphite layer in the unexposed $\mathrm{SiC}$ region. Raman spectroscopy is used to confirm the removal of the carbon layer after etching. 


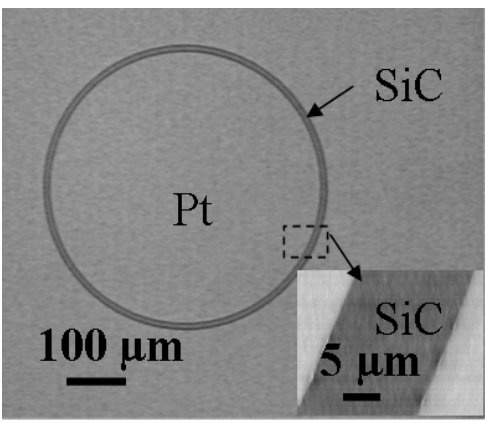

Figure 1: Optical and SEM image of CTLM structure. The radius of the ring is $250 \mu \mathrm{m}$, and the width of the gap is varied at $5 \mu \mathrm{m}, 10 \mu \mathrm{m}$, $15 \mu \mathrm{m}$ and $20 \mu \mathrm{m}$.

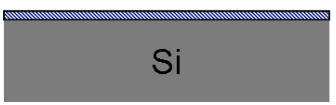

(a)

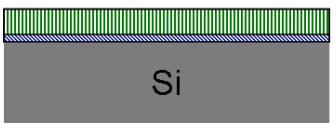

(b)

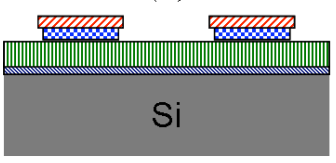

(c)

(d)

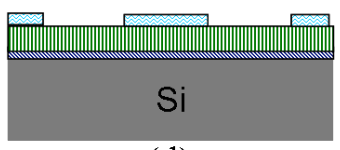

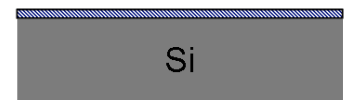

(a')

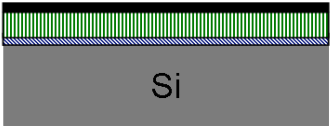

(b')

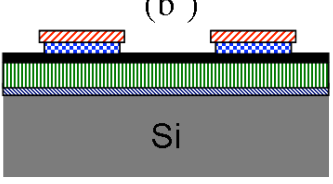

$\left(c^{\prime}\right)$

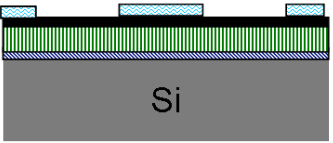

(d')

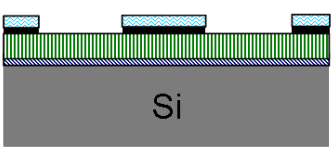

$\left(\mathrm{e}^{\prime}\right)$
- $\quad$ ming

$\mathrm{Si} \quad \mathrm{SiO}_{2} \quad \mathrm{SiC}$

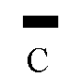

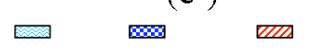

Pt G-line PR I-line PR
Figure 2: CTLM test structure fabrication process. (a)-(d), as-deposited poly-SiC fabrication process; $\left(a^{\prime}\right)-\left(e^{\prime}\right)$ annealed poly-SiC fabrication process.

\section{Testing setup}

After microfabrication, the samples are fixed in a 24-pin ceramic package, using Resbond 940LE ceramic adhesive, which can withstand up to $1370{ }^{\circ} \mathrm{C}$. The test structure is wirebonded to the package by $\mathrm{Al}$ wire, and the package pins are connected to the testing circuit by Durabond $952 \mathrm{Ni}$ adhesive, which can withstand up to $1100{ }^{\circ} \mathrm{C}$. Four-point $\mathrm{I}-\mathrm{V}$ measurement is realized by a Keithley model 2400 system to avoid parasitic resistance from the probe to metal contact and the testing circuits.

According to CTLM, the measured resistance (R) is:

$$
R=\frac{R_{s}}{2 \pi} \operatorname{In}\left(1+\frac{d}{r_{0}}\right)+\frac{R_{s}}{2 \pi} \sqrt{\frac{\rho_{c}}{R_{s}}}\left(\frac{1}{r_{0}}+\frac{1}{r_{0}+d}\right)
$$

where $R_{s}$ is the sheet resistance of the SiC film, $d$ and $r_{0}$ are the
CTLM gap width and radius, and $\rho_{c}$ is the contact resistivity. By measuring $R$, contact resistivity is calculated from Eq. 1 .

The samples are heated up by an Isotemp hotplate in air. After high temperature I-V measurement, the samples are characterized by a Siemens D5000 x-ray diffraction (XRD) to probe possible interfacial reactions.

\section{RESULTS AND DISCUSSION}

As shown in Fig. 3, the $\mathrm{SiC}$ transverse-optical (TO) and longitudinal-optical (LO) peak of the as-deposited and annealed samples indicate the cubic structure of the $\mathrm{SiC}$ film. The Raman TO peak of the as-deposited poly-SiC is located at around $790 \mathrm{~cm}^{-1}$, while that of the annealed poly-SiC is located at around $792 \mathrm{~cm}^{-1}$. The shift of the TO peak position $\left(v_{\mathrm{TO}}\right)$ away from the standard TO peak position $796 \mathrm{~cm}^{-1}$ has been used to characterize the in-plane bi-axial residual strain $\left(\varepsilon_{\mathrm{bi}}\right)$ of the single crystalline $3 \mathrm{C}-\mathrm{SiC}$ films grown [10]. The proposed strain induced Raman TO shift by deflecting suspended single crystalline $3 \mathrm{C}$ - $\mathrm{SiC}$ membrane is given by the empirical equation [9]:

$$
\varepsilon_{T O}=\frac{796-v_{T O}}{1125}
$$

As calculated from Eq. 2, the bi-axial strain of the as-deposited poly-SiC and the annealed poly-SiC are $0.51 \%$ and $0.33 \%$, respectively. The annealing leads to less tensile strain of the film.

For carbon structure, raman spectra for disordered and ideal graphite is dominated by two modes - the D and G modes, around $1350 \mathrm{~cm}^{-1}$ and $1580-1600 \mathrm{~cm}^{-1}$, respectively. The D mode is associated with disordered or defective hexagonal graphitic plane structures, while the $\mathrm{G}$ mode corresponds to stretching vibrations in the basal-plane of ideal graphite. From the carbon D and G peaks intensity, width and position, one can differentiate the carbon structure from nanocrystalline to amorphous carbons [11]. In Fig. 2, the $G$ peak for the annealed sample lies at $1595.8 \mathrm{~cm}^{-1}$, and the $\mathrm{D}$ peak is at $1345.5 \mathrm{~cm}^{-1}$. The intensity ratio of the two peaks, $\mathrm{I}(\mathrm{D}) / \mathrm{I}(\mathrm{G})=1.8$.is indicative of a highly defective, nanocrystalline nanocrystalline graphitic film. In order to study the effect of pre-annealing on the poly-SiC metallization performance, $\mathrm{Pt}$ to the as-deposited and annealed poly-SiC contacts are investigated next.

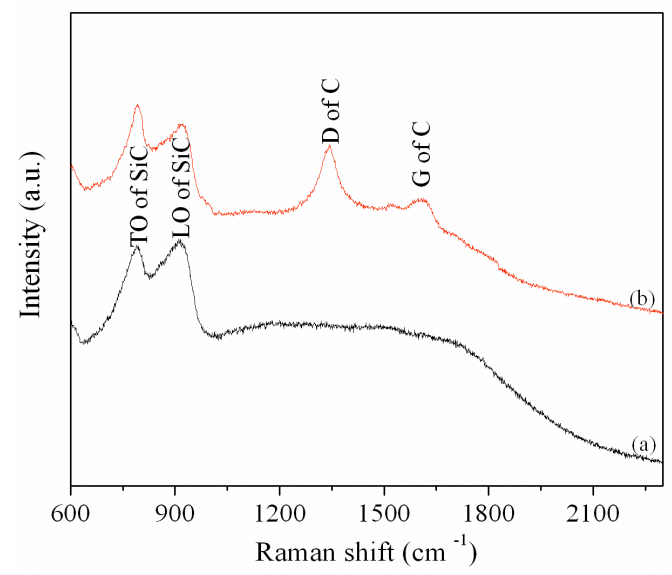

Figure 3: Raman spectra of (a) as-deposited poly-SiC, (b) after annealing at $1300^{\circ} \mathrm{C}$ under ultrahigh vacuum. 


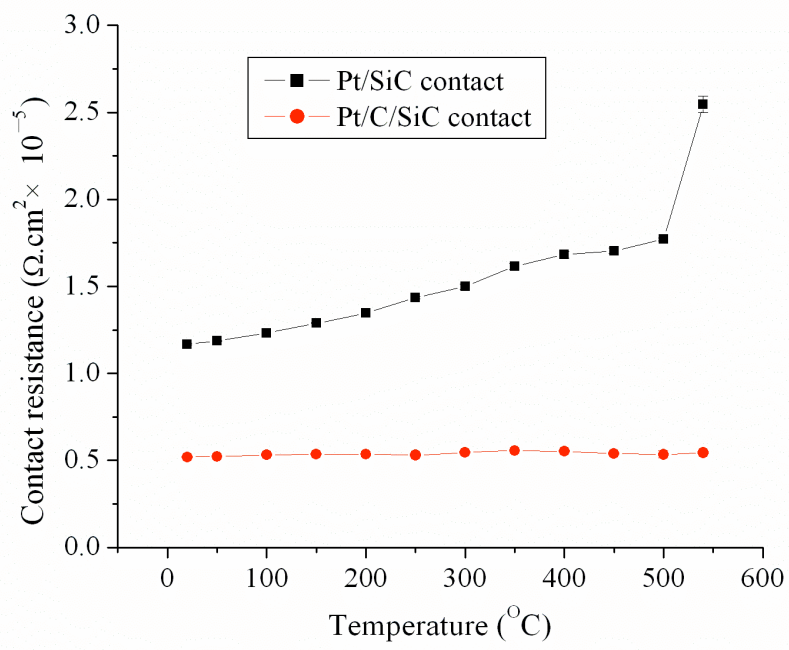

Figure 4: Pt to SiC contact resistivity vs. temperature for $3 \mathrm{~min}$ duration at each temperature.

The $\mathrm{Pt}$ to the as-deposited poly-SiC and the annealed poly-SiC contacts are both ohmic, and the contact resistivity from room temperature to $540{ }^{\circ} \mathrm{C}$ are calculated from Eq.1 and are shown in Fig.4, where $\mathrm{Pt} / \mathrm{SiC}$ refers to the $\mathrm{Pt}$ to the as-deposited poly-SiC contact, while $\mathrm{Pt} / \mathrm{C} / \mathrm{SiC}$ refers to the $\mathrm{Pt}$ to the annealed poly-SiC contact. The room temperature contact resistivity of the $\mathrm{Pt} / \mathrm{C} / \mathrm{SiC}$ contact is $5.2 \times 10^{-6} \Omega . \mathrm{cm}^{2}$, which is about half of the $\mathrm{Pt} / \mathrm{SiC}$ contact resistivity. $\mathrm{Pt} / \mathrm{SiC}$ contact increases progressively with temperature and reaches $2.5 \times 10^{-5} \Omega . \mathrm{cm}^{2}$ at $540{ }^{\circ} \mathrm{C}$. This is to be contrasted to the contact resistivity of the $\mathrm{Pt} / \mathrm{C} / \mathrm{SiC}$ contact, which exhibits little change with temperature.

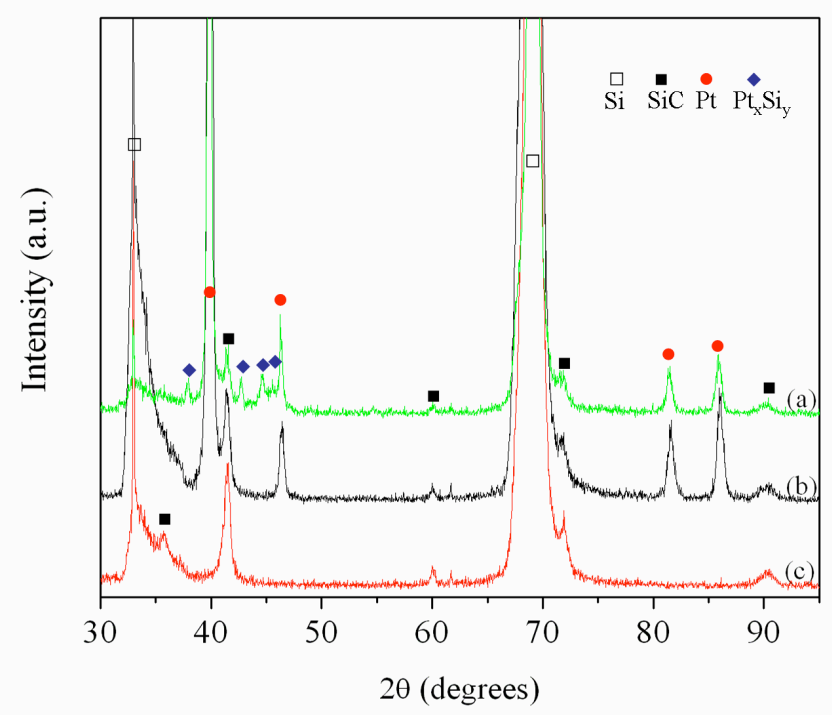

Figure 5: X-ray diffraction spectra of (a) Pt/SiC contact, (b) $\mathrm{Pt} / \mathrm{C} / \mathrm{SiC}$ contact (both after $540{ }^{\circ} \mathrm{C}$ testing in the air), (c) $\mathrm{SiC}$ film with surface Clayer.

The metal to semiconductor contact resistivity value is affected by the interfacial states. After annealing, the change in poly-SiC film stress and surface chemistry could both be responsible for the lower value of contact resistivity. It is known that tensile stress can be generated from voids and missing atoms in the grain boundaries of polycrystalline films. The larger the tensile stress, the higher the density of defects in the grain boundaries, which leads to increased electron scattering and larger contact resistivity. According to the strain analysis, the UHV annealing at $1300{ }^{\circ} \mathrm{C}$ leading to lower tensile strain of the poly-SiC film may be responsible for the decrease of the contact resistivity to $\mathrm{Pt}$. On the other hand, the presence of nanocrystalline graphite could further lower the contact resistivity to Pt. Lu et al., have demonstrated that the contact resistivity of $\mathrm{Ni}$ and $\mathrm{Co}$ to graphitic $\mathrm{SiC}$ surface is lower than that of the non-graphitic $\mathrm{SiC}$ surface contacts [12]. Our annealed poly-SiC results in a graphitic surface that can lead to further reduction of contact resistance.

In addition, the $\mathrm{Pt} / \mathrm{C} / \mathrm{SiC}$ contact shows enhanced stability at high temperature in air, as shown in Fig.2. In order to study the phase change after high temperature testing, XRD spectra of the $\mathrm{Pt} / \mathrm{SiC}$ and $\mathrm{Pt} / \mathrm{C} / \mathrm{SiC}$ contacts after exposure in air at $540{ }^{\circ} \mathrm{C}$ are shown in Fig. 5. In comparison to the as-deposited poly-SiC, the $\mathrm{Pt} / \mathrm{SiC}$ and $\mathrm{Pt} / \mathrm{C} / \mathrm{SiC}$ both show $\mathrm{Pt}(111), \mathrm{Pt}(220), \mathrm{Pt}(311)$ and $\mathrm{Pt}(222)$ peaks. In addition, the $\mathrm{Pt} / \mathrm{SiC}$ show $\mathrm{Pt}_{12} \mathrm{Si}_{5}(440), \mathrm{PtSi}(112)$, $\mathrm{PtSi}(202)$ and $\mathrm{Pt}_{6} \mathrm{Si}_{5}(611)$ phases, while no Pt silicide phase is observed in $\mathrm{Pt} / \mathrm{C} / \mathrm{SiC}$ contact after high temperature testing. The reaction between $\mathrm{Pt}$ and $\mathrm{SiC}$ may be responsible for the increase in contact resistivity of the $\mathrm{Pt} / \mathrm{SiC}$ contact structure. The presence of graphitic carbon builds a thermal barrier to the reaction between $\mathrm{Pt}$ and $\mathrm{SiC}$ leading to thermally stable contacts. It should be noted that oxidation of $\mathrm{Pt}$ or $\mathrm{SiC}$ may also change the contact resistivity. As future work, we will investigate the role of oxidation in $\mathrm{Pt} / \mathrm{SiC}$ and $\mathrm{Pt} / \mathrm{C} / \mathrm{SiC}$ contact structures.

\section{CONCLUSION}

In conclusion, the reduced tensile strain and formation of nanocrystalline interfacial graphite could both be responsible for the reduced ohmic contact resistivity of $\mathrm{Pt}$ to SiC. The controlled growth of interfacial nanocrystalline graphite, as presented here, could serve as a thermal barrier to the chemical reactions between $\mathrm{SiC}$ and metals, which opens the door to investigations of various metals to $\mathrm{SiC}$ contact studies and stable contact performance at elevated temperatures.

\section{REFERENCES}

[1] D. Gao, M. B. J. Wijesundara, C. Carraro, R. T. Howe, and R. Maboudian, "Recent Progress Toward A Manufacturable SiC Surface Micromachining Technology", IEEE Sens. J. 4, 441 (2004).

[2] S. Roy, R. G. DeAnna, C. A. Zorman and M. Mehregany, "Fabrication and Characterization of Polycrystalline $\mathrm{SiC}$ Resonators", IEEE Transactions on Electron Devices, 49, 2323 (2002).

[3] D.R. Myers, K.B. Cheng, B. Jamshidi, R.G. Azevedo, D.G. Senesky, L. Chen, M. Mehregany, M.B.J. Wijesundara, and A.P. Pisano, "Silicon carbide resonant tuning fork for microsensing applications in high-temperature and high G-shock environments," Journal of Micro/Nanolithography, MEMS, and MOEMS, 8,021116 (2009).

[4] L. M. Porter and R. F. Davis, "A Critical Review of Ohmic and Rectifying Contacts for Silicon Carbide", Materials Science and Engineering, B34, 83 (1995).

[5] J. Zhang, C. Carraro, R. T. Howe, and R. Maboudian, "Electrical, mechanical and metal contact properties of polycrystalline 3C-SiC films for MEMS in harsh environments," Surface \& Coatings Technology, 201, 8893 (2007). 
[6] J. H. Park and P. H. Holloway, "Effects of nickel and titanium thickness on nickel/titanium ohmic contacts to n-type silicon carbide", J. Vac. Sci. Technol. B, 23,486 (2005).

[7] A. K. Geim, "Graphene: Status and Prospects", Science 324, 1530 (2009).

[8] G. S. Marlow and M. B. Das, "The effects of contact size and non-zero metal resistance on the determination of specific contact resistance," Solid-State Electronics, 25, 91 (1982).

[9] F. Liu, C. Carraro, A. P. Pisano and R. Maboudian, "Growth and characterization of nitrogen-doped polycrystalline $3 \mathrm{C}$-SiC thin films for harsh environment MEMS applications", Journal of Micromechanics and Microengineering, 20, 03501 (2010).

[10] S. Rohmfeld, M. Hundhausen, L. Ley, C. A. Zorman and M. Mehregany, "Quantitative evaluation of biaxial strain in epitaxial 3C-SiC layers on $\mathrm{Si}(100)$ substrates by Raman spectroscopy", Journal of Applied Physics, 91, 1113 (2002).

[11] A. C. Ferrari and J. Robertson, "Interpretation of Raman spectra of disordered and amorphous carbon", Physical Review B, 61, 14094 (2000).

[12] W. Lu, W. C. Mitchel, G. R. Landis, T. R. Crenshaw, and W. Eugene Collins, "Catalytic graphitization and Ohmic contact formation on 4H-SiC", J. Appl. Phys. 93, 5397 (2003).

\section{ACKNOWLEDGEMENT}

The authors thank Siemens Corporate Research, Inc. (Award Number 20100118), NSF (Grant Number CMMI-0825531) for financial support. The authors also thank Sarah Wodin-Schwartz in Mechanical Engineering, University of California at Berkeley for supplying the high temperature adhesive.

\section{CONTACT}

*F. Liu, tel: +1-510-643-3489; fangliu@berkeley.edu 